\title{
Deep dry etching process development for photonic crystals in InP- based planar waveguides
}

\author{
Rob van der Heijden ${ }^{* a}$, Mischa S. P. Andriesse ${ }^{\mathrm{b}}$, Carl-Fredrik Carlström ${ }^{\mathrm{a}}$, Emile van der Drift ${ }^{\mathrm{b}}$, \\ Erik-Jan Geluk $^{\mathrm{a}}$, Rob W. van der Heijden ${ }^{\mathrm{a}}$, Fouad Karouta ${ }^{\mathrm{a}}$, Peter Nouwens ${ }^{\mathrm{a}}$, Y. Siang Oei ${ }^{\mathrm{a}}$, Tjibbe \\ de Vries ${ }^{\mathrm{a}}$, Huub W.M. Salemink ${ }^{\mathrm{a}}$ \\ ${ }^{a}$ COBRA Inter-University Research Institute, Eindhoven University of Technology, PO Box 513, \\ NL 5600 MB Eindhoven, The Netherlands \\ ${ }^{\mathrm{b}}$ Delft Institute for Microelectronics and Submicron Technology, Delft University of Technology, \\ P.O. Box 5053, 2600 GB Delft, The Netherlands
}

\begin{abstract}
Chlorine-based inductively coupled plasma etching processes are investigated for the purpose of etching twodimensional photonic crystals in InP-based materials. Etch rates up to $3.7 \mu \mathrm{m} / \mathrm{min}$ and selectivity's to the SiN mask up to 19 are reported. For the removal of indiumchloride etch products both the application of elevated temperatures and high ion energy's are investigated. The reactor pressure is an important parameter, as it determines the supply of reactive chlorine. It is shown, that $\mathrm{N}_{2}$ passivates feature sidewalls during etching, improving the anisotropy. Ions that impact onto the sidewalls, either directly or after scattering with the SiN-mask or hole interior, cause sidewall etching. Highly directional ion bombardment and vertical sidewalls in the SiN-mask are therefore crucial for successful etching of fine high aspect ratio structures.
\end{abstract}

Keywords: Photonic crystal, InP, ICP etching

\section{INTRODUCTION}

Photonic crystals may be used for various functions in photonic integrated circuits. Integration of two-dimensional (2D) photonic crystals with these planar optical circuits can be done with available lithographic techniques. Conventional index guiding must account for vertical confinement in these 2D systems. The InP-material system is relevant for applications at the long-haul telecommunication free space wavelength of $1550 \mathrm{~nm}$. For photonic crystals in the InPmaterial system, two intrinsic low-loss limits exist: on the one hand high refractive index contrast air-bridge type crystals and on the other hand low index contrast InP-InGaAsP buried waveguide type crystals ${ }^{1}$. Successful fabrication of optical devices in air-bridge type InP-based photonic crystals has been reported recently ${ }^{2,3}$. However, these free standing $\sim 250 \mathrm{~nm}$ thick membranes are not practical for use in photonic integrated circuits because of their mechanical fragility, poor thermal properties and modal mismatch with InP-InGaAsP ridge waveguides. Therefore, for photonic integrated circuits applications our focus is on hole-type 2D photonic crystals in low contrast InP-InGaAsP waveguides.

To obtain a sufficiently wide photonic band gap centered around $1550 \mathrm{~nm}$, the crystal must have a lattice constant $a$ of about $400 \mathrm{~nm}$ and the holes must have a diameter $d$ of about $200 \mathrm{~nm}$. Despite the index guiding for vertical confinement, intrinsic out-of-plane optical losses inevitably occur ${ }^{1}$. To prevent additional losses, the holes must be etched sufficiently deep to overlap with the optical mode of the planar waveguide structure ${ }^{4}$. An aspect ratio of about 10 is therefore required. Furthermore, the sidewalls of the holes must be vertical and smooth to prevent further scattering losses ${ }^{5}$. Conventional parallel plate Reactive Ion Etching (RIE) with $\mathrm{CH}_{4}$-based chemistry, which is a standard process for etching InP-based ridge waveguides, is not capable to meet these requirements as it produces barrel-shaped holes with insufficient aspect ratio ${ }^{6}$. Therefore, advanced deep etching techniques as Electron Cyclotron Resonance (ECR) etching ${ }^{7}$, Chemically Assisted Ion Beam Etching (CAIBE) ${ }^{8}$ and Inductively Coupled Plasma (ICP) etching ${ }^{9,10}$ have been recently used for etching hole-type photonic crystals in InP-based materials.

\footnotetext{
*e-mail: r.v.d.heijden@tue.nl
} 
In this paper, we report on an investigation of chlorine-based ICP-processes for the fabrication of high aspect ratio holetype 2D photonic crystals in InP. Different gas compositions were selected to compare etching with a reactive gas only $\left(\mathrm{Cl}_{2}\right)$, reactive gas with an independent and inert sputtering component $\left(\mathrm{Cl}_{2} / \mathrm{Ar}\right)$ and a reactive gas with a component capable of surface passivation $\left(\mathrm{Cl}_{2} / \mathrm{N}_{2}\right)$. The balance between supply of reactive species and removal rate of etch products is crucial in $\mathrm{Cl}_{2}$-based InP-etching ${ }^{11}$. Therefore, the influence of temperature, DC-bias and pressure was investigated and a good process window was determined.

\section{EXPERIMENTAL}

All experiments were performed on (100) n-type Sn-doped InP samples with a size of approximately $8 \times 8 \mathrm{~mm}^{2}$. A SiNlayer was deposited onto the InP by Plasma Enhanced Chemical Vapor Deposition (PECVD). This SiN layer served as a mask to facilitate the final InP-etching step. A PMMA $950 \mathrm{~K}$ e-beam resist layer was deposited onto the SiN by spincasting. The photonic crystal pattern was defined in this layer by e-beam lithography in the approximate center of the sample. The pattern was then transferred to the SiN-layer with a fluorine based RIE-process. The remaining PMMA was removed with a low-bias oxygen-plasma. Prior to the final ICP-etching step, the (native) oxide layer was removed from the surface by wet chemical etching in a $\mathrm{H}_{3} \mathrm{PO}_{4}: \mathrm{H}_{2} \mathrm{O}=1: 10$ solution. To characterize the etch result, the samples were cleaved through the etched structures and inspected by cross-sectional scanning electron micrsocopy (XSEM)

To evaluate the ICP-processes, patterns of stripes and triangular lattices of holes with different dimensions were fabricated in both 250 and $400 \mathrm{~nm}$ thick SiN-layers. In figure 1, XSEM images after pattern transfer to the SiN-mask and PMMA-removal are shown for different structures in $400 \mathrm{~nm}$ thick SiN mask layers.
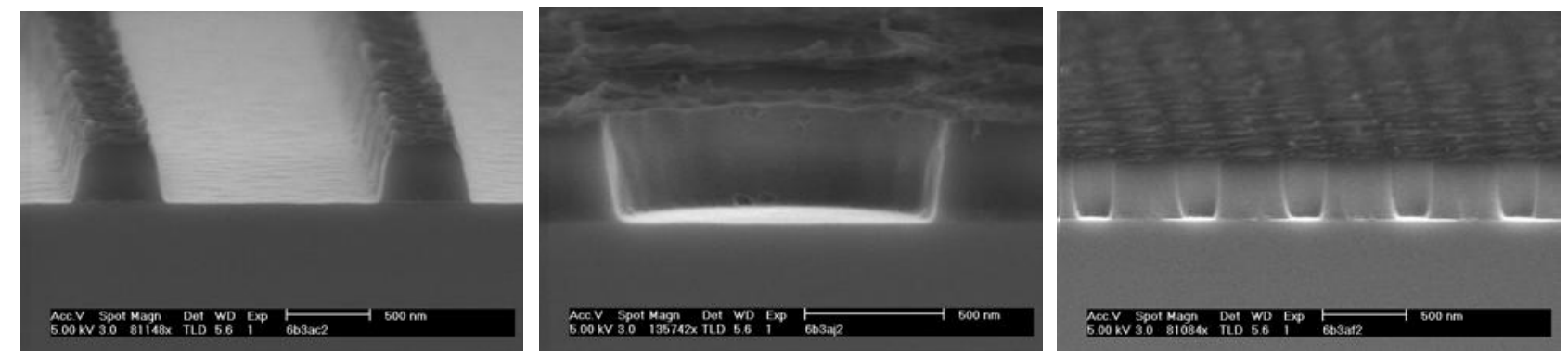

Figure 1: XSEM images of SiN mask structures after RIE and PMMA-removal. From left to right: $1.4 \mu \mathrm{m}$ lines, $1.1 \mu \mathrm{m}$ wide holes and $0.2 \mu \mathrm{m}$ wide holes in $400 \mathrm{~nm}$ thick SiN. Notice the non-ideal sloped sidewalls for all structures.

Etch experiments were carried out in a load-locked Alcatel MET system and a load-locked Oxford Plasmalab 100 system. In both ICP-systems, samples were placed on a 4 in. carrier wafer, which was made either of stainless steel (MET) or silicon (Plasmalab). For the experiments at elevated temperature in the MET-reactor, the samples were glued to the wafer with heat conducting paste to ensure thermal contact between sample and wafer. A He backflow provided thermal contact between the wafer and the substrate holder. The temperature of the substrate holder was kept to a preset value by a combination of constant liquid nitrogen- (MET) or water (Plasmalab) cooling and regulated resistive heating. In the MET-system, the substrate temperature was measured with a Luxtron fluoroptic probe. This probe was placed in the He-backflow, less than $1 \mathrm{~mm}$ from the wafer. In the Plasmalab system, the temperature was measured by a thermocouple. It should be pointed out here, that the sample temperature was significantly higher than the measured substrate temperature due to heating from the ion bombardment during etching ${ }^{12}$. Throughout the experiments, the ICP source input power was $1000 \mathrm{~W}$ in both etching systems.

\section{RESULTS}

In this section the influence of the systematically varied ICP-parameters on hole profile and etch rate are presented and discussed. 


\subsection{Temperature dependence of $\mathrm{Ar} / \mathrm{Cl}_{2}$-process}

The temperature dependence of the InP etching is investigated in the MET reactor for a process with an Ar-flow of 75 sccm and a $\mathrm{Cl}_{2}$-flow of $25 \mathrm{sccm}$. The pressure in the reactor was $1 \mathrm{~Pa}$ and the DC-bias was set to $-100 \mathrm{~V}$. Figure 2 shows the temperature-dependence of the etch rate. From this Arrhenius plot, the activation energy is determined to be $(0.52 \pm 0.05) \mathrm{eV}$. This value is consistent with a value found elsewhere ${ }^{12}$, for a regime where the vapor pressure of the indium chloride etch products is lower than the etch chamber pressure.

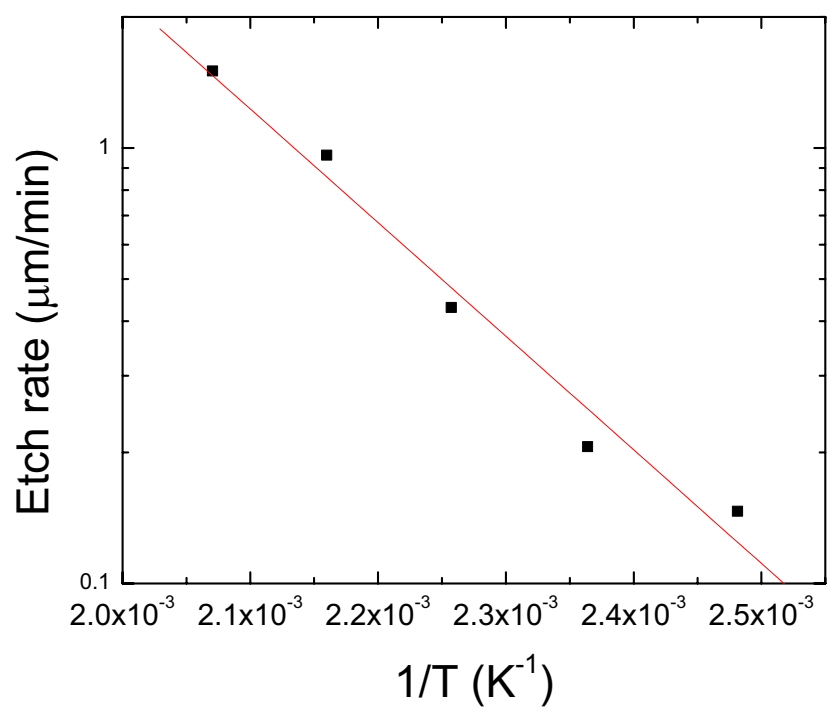

Figure 2: Arrhenius plot of the wide area InP-etch rate for the $\mathrm{Ar} / \mathrm{Cl}_{2}$-process. The line is a linear fit of the data points. The calculated activation energy is $(0.52 \pm 0.05) \mathrm{eV}$.

The rate limiting step which causes the Arrhenius dependence of the InP etch rate is thus believed to be desorption of the indium chloride etch products. Etching at elevated temperatures or at high ion energy is necessary because of the relatively low volatility of these products ${ }^{13}$. The SiN etch rate is $0.13 \mu \mathrm{m} / \mathrm{min}$, almost independent of temperature. For a wide area, an InP:SiN selectivity of 12 is obtained for this process at $210{ }^{\circ} \mathrm{C}$.

In figure 3, XSEM images of the sidewall of $5 \mu \mathrm{m}$ wide stripes are shown after 2 minutes of etching at different substrate temperatures.
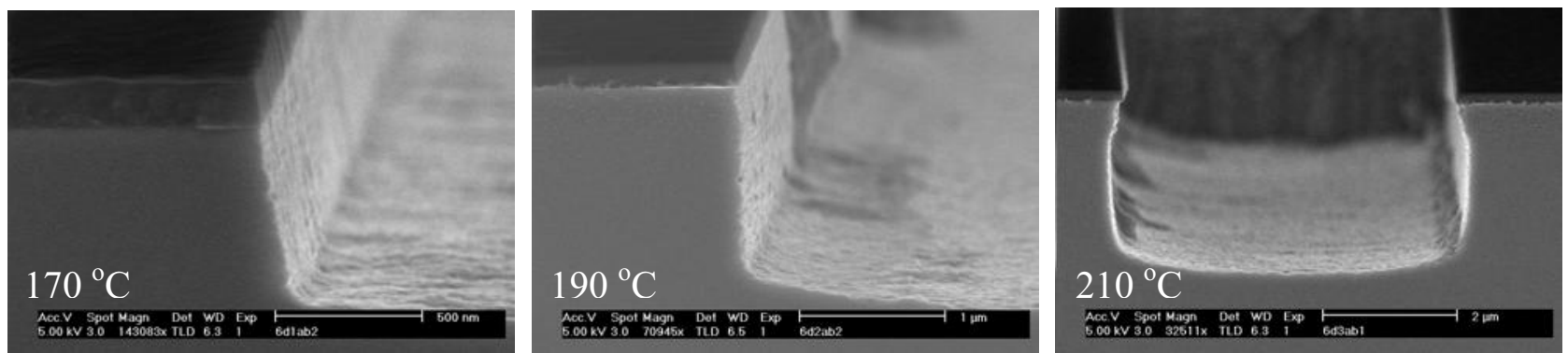

Figure 3: XSEM images of $5 \mu \mathrm{m}$ wide stripes after 2 minutes of etching in the $\mathrm{Ar} / \mathrm{Cl}_{2}$-plasma for different temperatures (see inset in figures). A considerable amount of the SiN-mask is still present after etching, as visible next to the etched stripe. The sidewall of the etched stripe changes with temperature from positively sloped to negatively sloped with vertical sidewalls at $190{ }^{\circ} \mathrm{C}$. The sidewalls and bottom exhibit a similar type of roughness. At $210^{\circ} \mathrm{C}$ mask undercut occurs due to lateral chemical etching. 
From figure 3, a transition from positively to negatively sloped sidewall is apparent. A similar transition was observed previously as a function of $\mathrm{Cl}_{2}$ content in the plasma ${ }^{14}$ and was attributed to the balance between the physical and chemical etch component. At $190{ }^{\circ} \mathrm{C}$, the etching is balanced and sidewalls are straight. The mask undercut occurring at $210{ }^{\circ} \mathrm{C}$ suggests that this temperature is too high for etching the fine high aspect ratio structures, unless lateral etching can be prevented by a passivation mechanism.

\subsection{Addition of $\mathbf{N}_{2}$}

It can be expected, that $\mathrm{N}_{2}$ is capable of passivation of the InP surface to prevent chemical lateral etching. To investigate this effect, samples were etched in both $\mathrm{Ar} / \mathrm{Cl}_{2}$ - and $\mathrm{N}_{2} / \mathrm{Cl}_{2}$-chemistry in the MET reactor with an Ar/ $\mathrm{N}_{2}$-flow of $75 \mathrm{sccm}$ and a $\mathrm{Cl}_{2}$-flow of $25 \mathrm{sccm}$. The substrate temperature was set to $220{ }^{\circ} \mathrm{C}$ to ensure chemical lateral etching in the $\mathrm{Ar} / \mathrm{Cl}_{2}$ case. Pressure and DC-bias were kept the same as in the previous experiment. XSEM images of different structures after etching are shown for the different chemistries in figure 4.
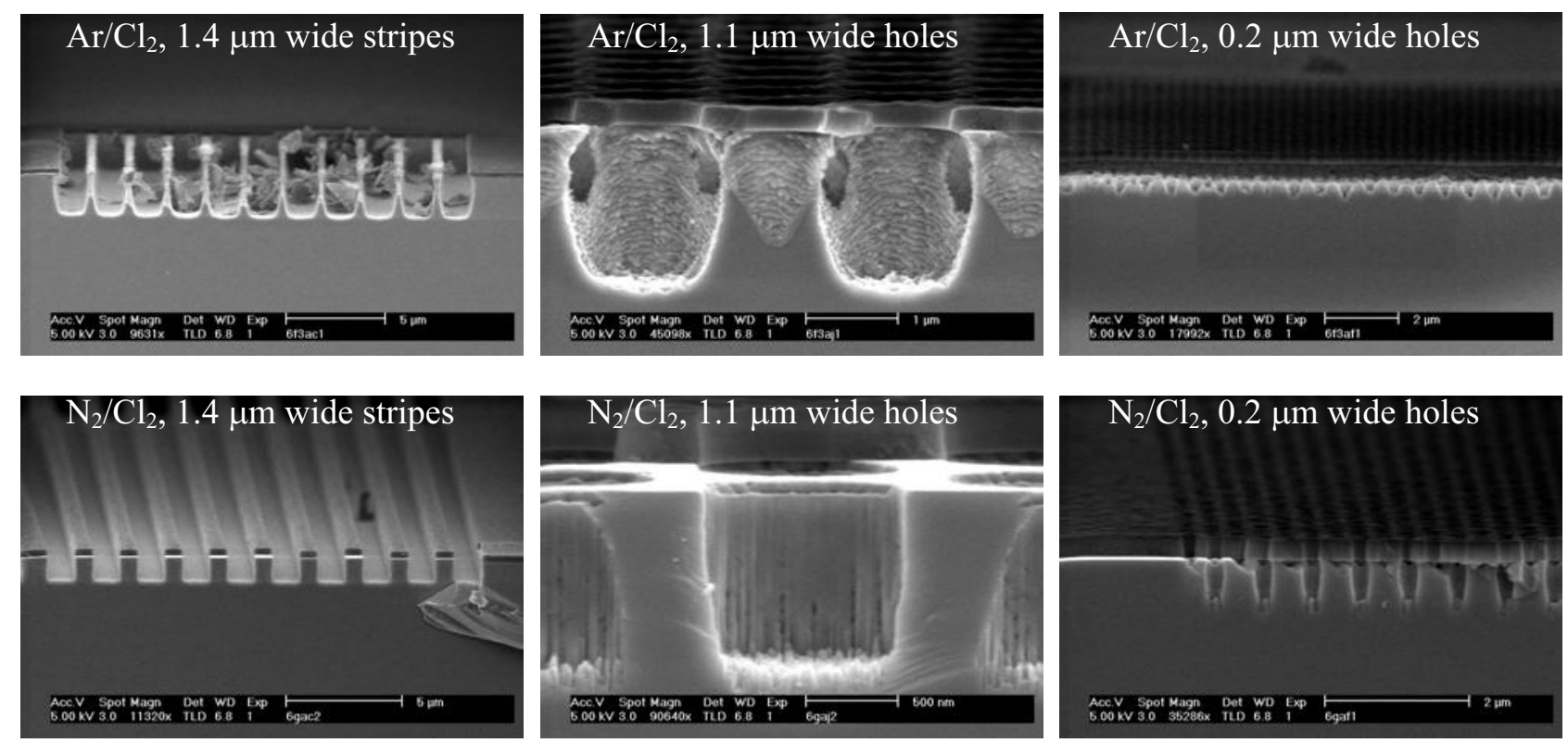

Figure 4: XSEM images of different structures (see inset in figures) etched for 2 minutes in $\mathrm{Ar} / \mathrm{Cl}_{2}-$ and $\mathrm{N}_{2} / \mathrm{Cl}_{2}$-chemistry at $220^{\circ} \mathrm{C}$. For the $\mathrm{N}_{2} / \mathrm{Cl}_{2}$ etched $1 \mu \mathrm{m}$ holes, the front part of the mask was unintentionally removed during cleaving. Notice the difference in vertical etching, lateral etching, sidewall roughness and bottom roughness between the two chemistries. For the $0.2 \mu \mathrm{m}$ holes etched with $\mathrm{Ar} / \mathrm{Cl}_{2}$, the InP is completely under etched, leaving the $\mathrm{SiN}$ as a freestanding membrane (upper right).

The addition of $\mathrm{N}_{2}$ reduces the lateral etching considerably, which is attributed to sidewall passivation. It is found elsewhere for (001) InP that under impact of $\sim 100 \mathrm{eV} \mathrm{N}^{+}$-ions, mainly N-P bonds are formed ${ }^{15}$. It is speculated that formation of these N-P bonds competes with formation of $\mathrm{In}-\mathrm{Cl}$ bonds and therefore inhibits etching. XPS measurements to investigate the $\mathrm{N}_{2}$-passivation mechanism are in progress. The etching with $\mathrm{N}_{2} / \mathrm{Cl}_{2}$-chemistry is anisotropic, but considerable sidewall bowing is observed, which is more pronounced for narrow features. The vertical large area etch rate is a factor of 2.5 lower compared to the $\mathrm{Ar} / \mathrm{Cl}_{2}$-process, which is explained by reduced ion current density with a factor of 1.5, as measured with a Langmuir probe and passivation of the bottom surface. The InP:SiN selectivity for wide area etching is also reduced to 8.7. It is noted here, that the etch depth of the $0.2 \mu \mathrm{m}$ wide holes is a factor of 2.1 smaller than the large area etch depth. The striations on the sidewall as visible for the $1 \mu \mathrm{m}$ holes most likely originate from residual imperfections of the SiN-mask.

\subsection{Dependence on $\mathrm{N}_{2} / \mathrm{Cl}_{2}$-ratio}

The dependence on gas composition is investigated for $\mathrm{N}_{2} / \mathrm{Cl}_{2}$-chemistry in the MET reactor with a total gas flow of 100 sccm. Pressure, DC-bias and substrate temperature were kept the same as in the previous experiment. The etch depth for 
holes of different width after 2 minutes of etching is displayed as a function of $\mathrm{Cl}_{2}$-content in figure 5. XSEM images of $0.65 \mu \mathrm{m}$ wide holes after 2 minutes of etching at the same conditions are shown in figure 6 .

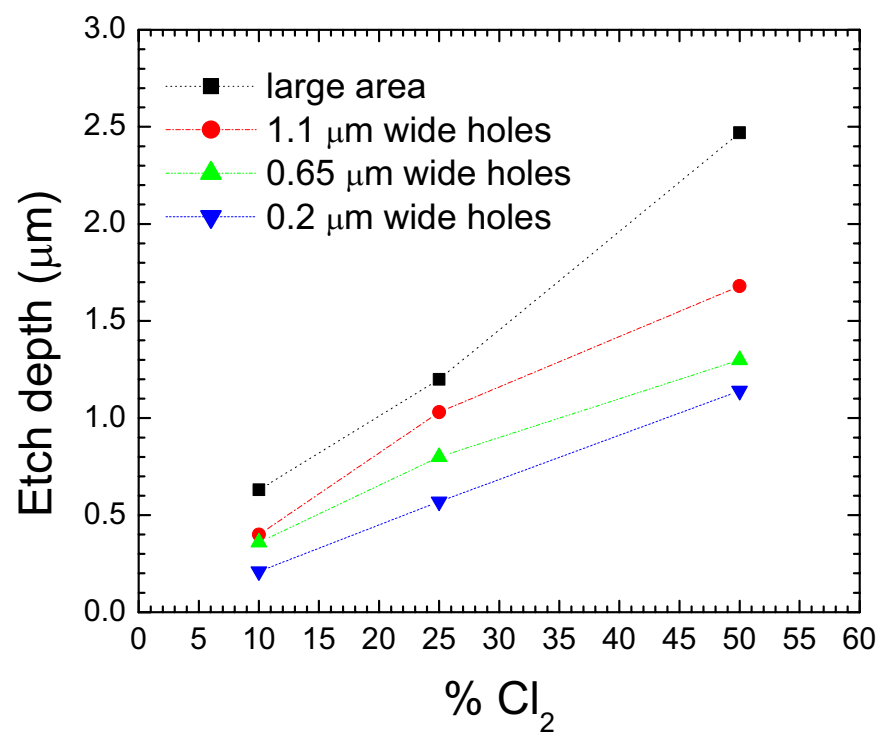

Figure 5: Etch depth as a function of $\mathrm{Cl}_{2}$-content for different structures. Etch depth is given rather than etch rate, because the etch rate is not constant in time for high aspect ratio features. It is observed that the etch depth is proportional to the $\% \mathrm{Cl}_{2}$ in the gas flow.
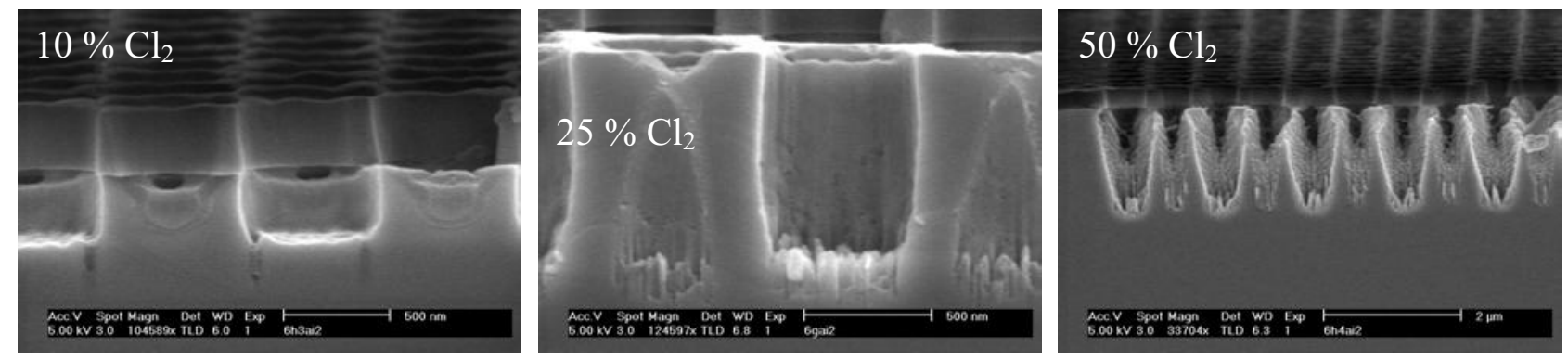

Figure 6: XSEM images of $0.65 \mu \mathrm{m}$ wide holes after etching for different $\mathrm{Cl}_{2}$-content (see inset in figures). For the holes etched with $25 \% \mathrm{Cl}_{2}$, the front part of the mask was unintentionally removed during cleaving. Note the difference in scale.

The etch depth is proportional to the $\% \mathrm{Cl}_{2}$ in the gas flow, as shown in figure 5 . It is visible in figure 6 , that the lateral etch rate does not change significantly going from $10 \%$ to $25 \% \mathrm{Cl}_{2}$, but increases dramatically going from $25 \%$ to 50 $\% \mathrm{Cl}_{2}$. The presumed competition between passivation (formation of N-P bonds) and etching (formation of In-Cl bonds) both on sidewall and bottom could explain this behaviour. In figure 5 it is visible, that the etch depth depends on the feature width. This lag-effect is well-known in plasma-etching ${ }^{16}$. The grass type roughness in the center image of figure 6 , may be due to micromasking by passivated islands at the bottom The holes etched with $10 \%$ and $25 \% \mathrm{Cl}_{2}$ show similar sidewall bowing, which indicates that this profile is due to non-vertical impact of ions that depassivate the sidewall. At low chlorine content, physical sputtering appears to be an important etching mechanism, as indicated by the observed trenches at the side of the holes.

\section{4. $\mathrm{N}_{2} / \mathrm{Cl}_{2}$-chemistry: influence of DC-bias}

The influence of DC-bias is investigated for $\mathrm{N}_{2} / \mathrm{Cl}_{2}$-chemistry in the MET reactor with a $\mathrm{N}_{2}$-flow of $75 \mathrm{sccm}$ and a Cl $\mathrm{Cl}_{2}$ flow of $25 \mathrm{sccm}$. Pressure and substrate temperature were kept the same as in the previous experiment. Figure 7 shows 
XSEM images of $0.2 \mu \mathrm{m}, 0.65 \mu \mathrm{m}$ and $1.1 \mu \mathrm{m}$ wide holes after 2 minutes of etching with $-100 \mathrm{~V}$ and $-200 \mathrm{~V}$ bias voltage.
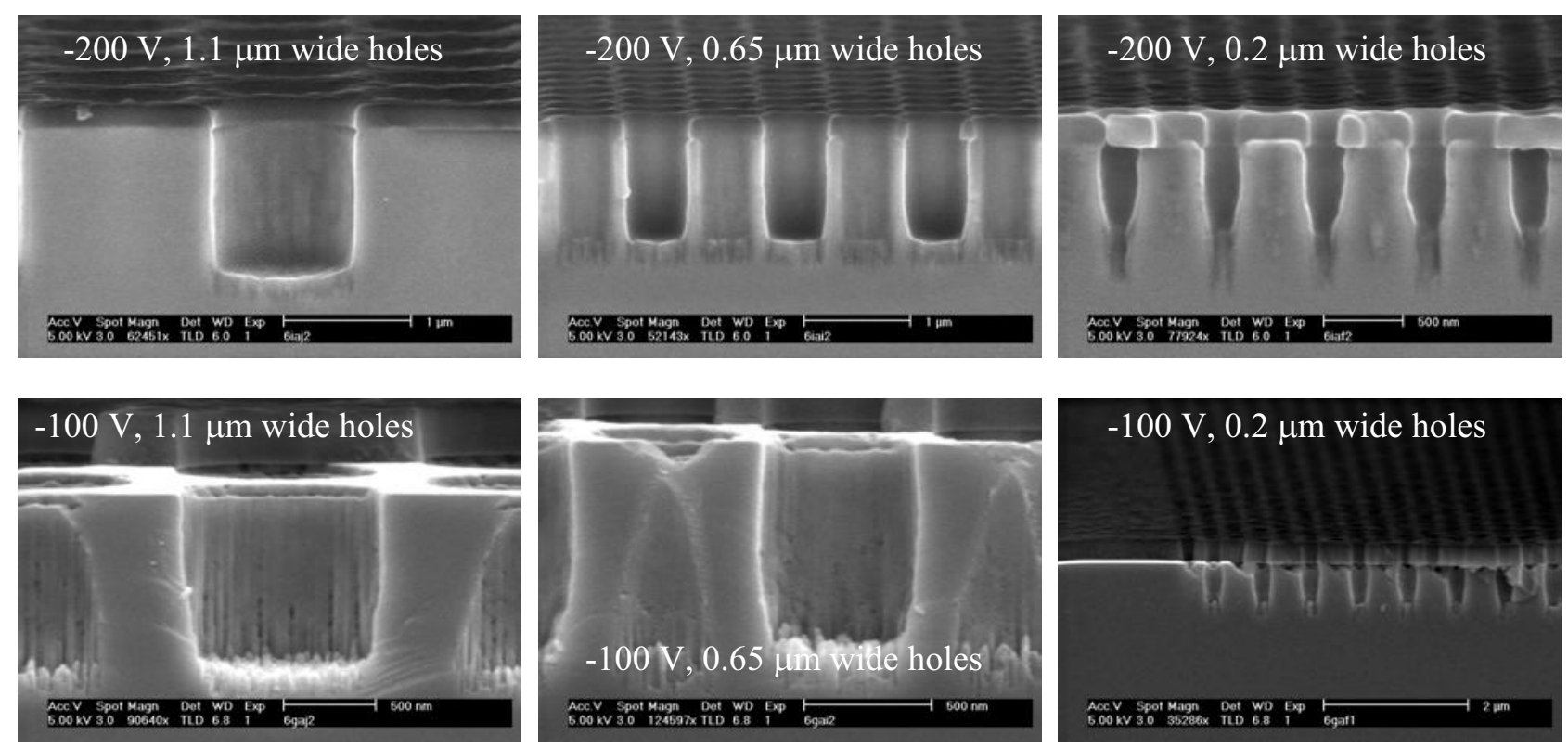

Figure 7: XSEM results of the etching of different structures (see inset figures) with $-200 \mathrm{~V}$ and $-100 \mathrm{~V}$ bias. The $1.1 \mu \mathrm{m}$ wide holes etched at $-200 \mathrm{~V}$ bias exhibit smooth and vertical sidewalls, the $0.65 \mu \mathrm{m}$ holes are slightly bowed and the $0.2 \mu \mathrm{m}$ wide holes suffer from severe sidewall bowing.

The wide area InP-etch rate increases with a factor of 1.3 going from $-100 \mathrm{~V}$ to $-200 \mathrm{~V}$ bias, while the selectivity is reduced with a factor of 1.4. The sidewalls are vertical for the $1.1 \mu \mathrm{m}$ holes, slightly bowed for the $0.65 \mu \mathrm{m}$ and severely bowed for the $0.2 \mu \mathrm{m}$ wide holes etched at $-200 \mathrm{~V}$ bias, see top row of figure 7 . From a comparison with the results for $-100 \mathrm{~V}$ bias, see bottom row of figure 7 , it is concluded that the mechanism for sidewall etching depends on feature width. Besides direct non-vertical impact of ions on the sidewall because of the ion angular distribution, ions are also scattered from the SiN-mask or from the feature interior. These scattered ions only reach the opposite sidewall in narrow features and sidewall bowing is therefore more pronounced when the feature-width is small. The directionality of the ion-bombardment is expected to be enhanced at higher bias, which reduces the non-vertical impact of ions. This could explain the vertical sidewalls of the $1.1 \mu \mathrm{m}$ holes. Note the trenches at the bottom of the $0.2 \mu \mathrm{m}$ wide holes in comparison with the $-100 \mathrm{~V}$ result. This again shows the significance of physical sputtering for the etching process.

\subsection{Pure $\mathrm{Cl}_{2}$-chemistry at low temperature: influence of DC-bias}

Experiments with pure $\mathrm{Cl}_{2}$-chemistry are performed in the Plasmalab 100 reactor with a $\mathrm{Cl}_{2}$-flow of $7 \mathrm{sccm}$. The pressure in the reactor was $0.5 \mathrm{~Pa}$ and the substrate temperature was $60{ }^{\circ} \mathrm{C}$. Because of this relatively low temperature, a relatively high ion energy is used to ensure desorption of the indiumchloride etch products. Therefore the influence of DC-bias was investigated for this process. The wide area InP-etch rate as a function of DC-bias is shown in figure 8. The InP:SiN selectivity for this process is 19 at a bias voltage of $-230 \mathrm{~V}$. XSEM pictures of $0.23 \mu \mathrm{m}$ wide holes after 1 minute of etching at the same conditions are presented in figure 9. 


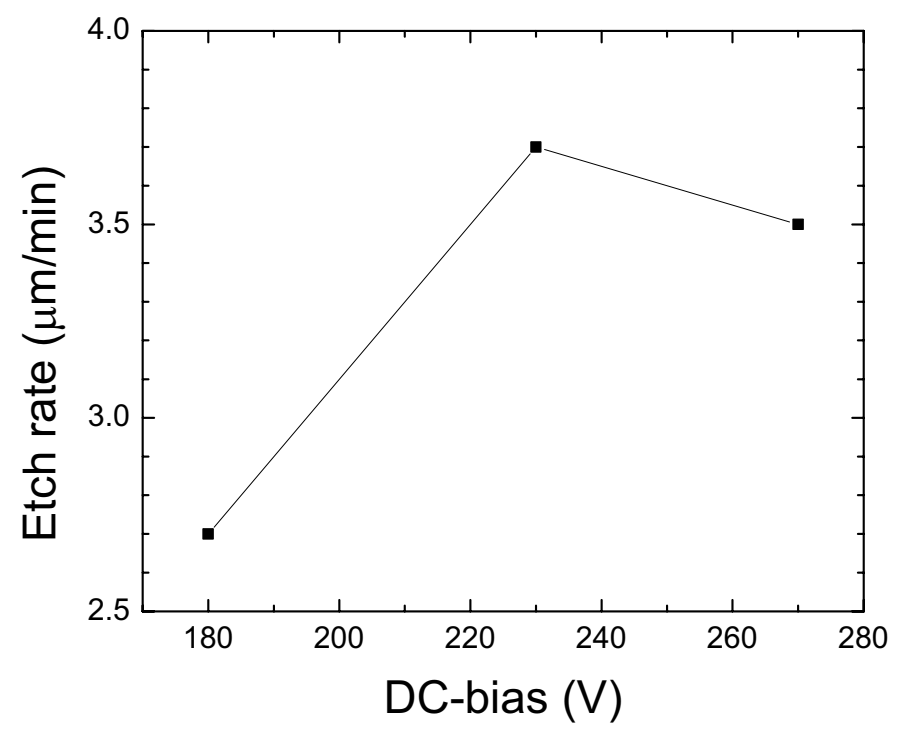

Figure 8: Wide area InP-etch rate as a function of DC-bias with pure $\mathrm{Cl}_{2}$-chemistry after 1 minute of etching.
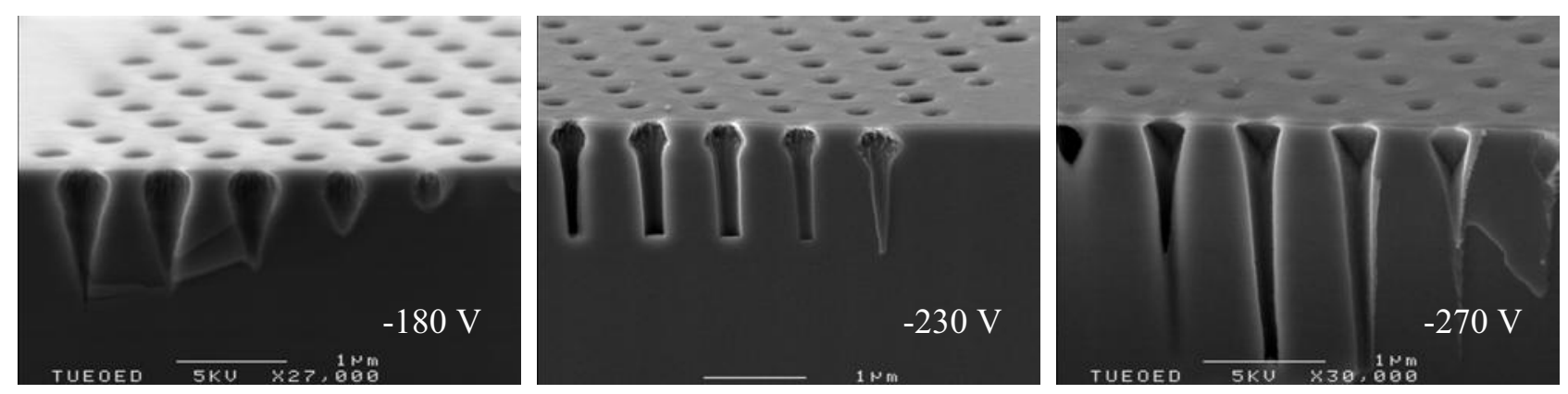

Figure 9: XSEM results of the etching of $0.23 \mu \mathrm{m}$ wide holes at different DC-bias (see inset figures).

The etch result for $0.23 \mu \mathrm{m}$ wide holes is strongly dependent on DC-bias. At $-230 \mathrm{~V}$ the holes exhibit straight sidewalls and a flat bottom. The wide top ('neck') was also observed in hole-etching experiments with CAIBE and was attributed to ions scattering from the SiN-mask or the hole interior ${ }^{8}$. Lower DC-bias yields conical shaped holes, while higher DCbias results in holes with a slightly sloped sidewall. The etch depth of the narrow holes increases with a factor of $>2$, going from $-230 \mathrm{~V}$ to $-270 \mathrm{~V}$, while the wide area etch rate does not change significantly. Further experiments to clarify this behavior are in progress.

\subsection{Influence of pressure}

The influence of pressure is investigated for pure $\mathrm{Cl}_{2}$-chemistry in the Plasmalab reactor. The $\mathrm{Cl}_{2}$-flow and substrate temperature were kept the same as in the previous experiment. Here, the bias power was kept constant, which implied that the DC-bias increased with pressure. The wide area InP-etch rate is shown in figure 10 as a function of pressure. There is an optimum in etch rate in between 0.1 and $1 \mathrm{~Pa}$. 


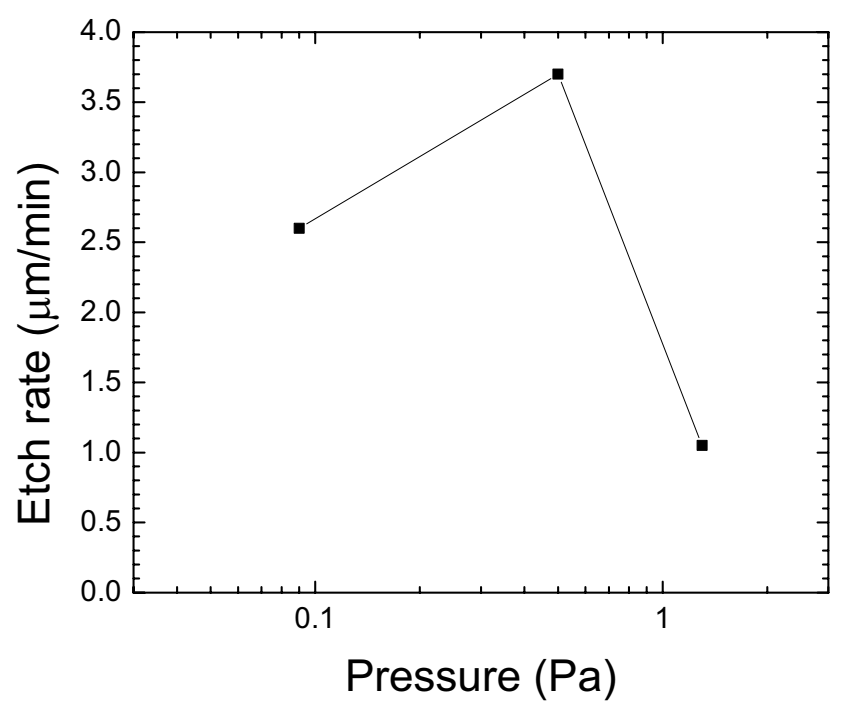

Figure 10: Wide area InP-etch rate as a function of pressure at constant bias power of $100 \mathrm{~W}$. Note the logarithmic pressure-scale.

XSEM images of a $10 \mu \mathrm{m}$ wide stripe and $0.23 \mu \mathrm{m}$ wide holes after etching for 1 minute at different pressures are shown in figure 11 .
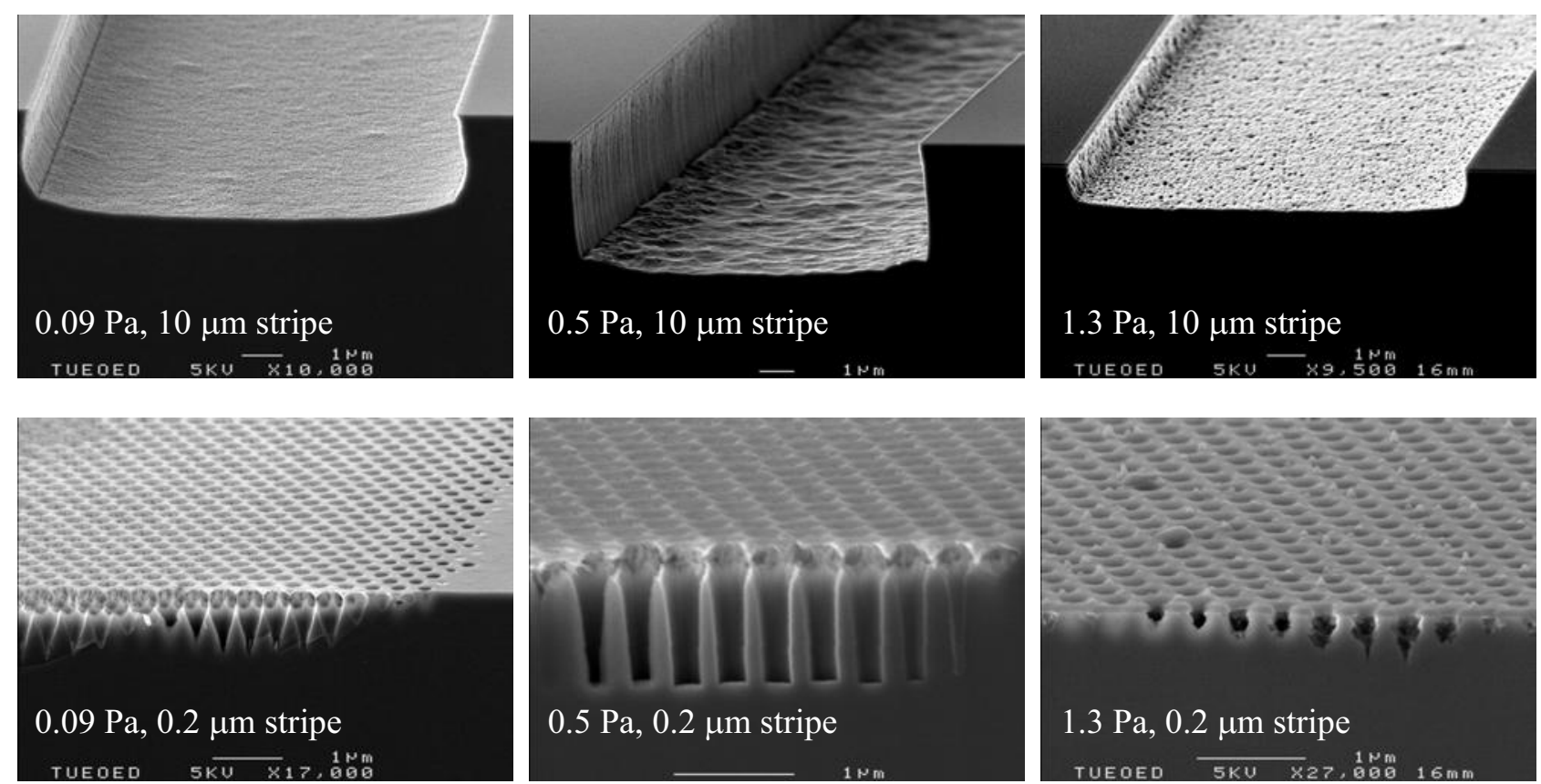

Figure 11: XSEM images of a $10 \mu \mathrm{m}$ wide stripe and $0.23 \mu \mathrm{m}$ wide holes etched for 1 minute different pressures (see inset figures). The values of the DC-bias are $-180 \mathrm{~V}$ at $0.09 \mathrm{~Pa},-230 \mathrm{~V}$ at $0.5 \mathrm{~Pa}$ and $-335 \mathrm{~V}$ at $1.3 \mathrm{~Pa}$.

An optimum in etch rate as a function of pressure is expected for this process because there is a balance between removal of etch products and supply of reactive species ${ }^{11}$. At high pressure, an indiumchloride selvedge layer forms, which inhibits etching. At low pressure, the etching is limited by the supply of reactive chlorine. It is clear from figure 
11, that etching is inhibited at 1.3 Pa, even though the DC-bias is relatively high. The result for $0.09 \mathrm{~Pa}$ is most probably dominated by the relatively low bias voltage of $-180 \mathrm{~V}$ (see caption figure 11) and needs further investigation.

\section{CONCLUSIONS}

Removal of non-volatile indiumchloride is a rate limiting factor for $\mathrm{Cl}_{2}$-based InP etching, so that elevated temperature, high ion energy, or a combination of these is necessary for etching InP-based photonic crystals with sufficiently high etch rate. Etch experiments are performed at elevated temperature with relatively low ion energy. It is shown, that the etch rate in an $\mathrm{Ar} / \mathrm{Cl}_{2}$-process follows an Arrhenius dependence with an activation energy of $(0.52 \pm 0.05) \mathrm{eV}$. For this process, a balance between physical and chemical etching results in vertical sidewalls at a substrate temperature of $190^{\circ} \mathrm{C}$. Etch experiments are also performed with relatively high ion energy at $60{ }^{\circ} \mathrm{C}$. Vertical sidewalls are obtained for $-230 \mathrm{~V}$ bias voltage, but the top of the holes was significantly widened. This widening is attributed to ions scattered from the SiN-mask. It is found, that addition of $\mathrm{N}_{2}$ to the plasma yields vertical sidewalls, even at temperatures up to $220{ }^{\circ} \mathrm{C}$. The lateral etch rate is inhibited by passivation of the sidewalls, most probably by formation of N-P bonds. However sidewall bowing is observed for this process, which is more pronounced for narrow features. The sidewall bowing is independent of $\mathrm{Cl}_{2}$-content below $25 \% \mathrm{Cl}_{2}$. This indicates that the curved profile is due to ions that impact onto the sidewall, either directly because of the ion angular distribution or after scattering from the SiN-mask or the hole interior. The bowing is more pronounced for narrow features, because the scattered ions can reach the opposite sidewall in these features. By increasing the DC-bias, which narrows the ion angular distribution, the sidewall bowing is eliminated for wide features, but not for narrow features. It is expected that more vertical sidewalls in the SiN-mask are necessary for anisotropic etching of fine high aspect ratio holes with the $\mathrm{N}_{2} / \mathrm{Cl}_{2}$-process. From an investigation of the influence of pressure for the low temperature pure $\mathrm{Cl}_{2}$-process, it followed that etching is inhibited above $\sim 1 \mathrm{~Pa}$. This occurs because the removal of the etch products is much slower than the supply of reactive $\mathrm{Cl}_{2}$. The difference in pressure could explain the lower etch rate at elevated temperature, compared to the experiments at $60^{\circ} \mathrm{C}$.

\section{ACKNOWLEDGEMENTS}

Part of this research is supported by NanoNed, a technology programme of the Dutch ministry of Economic Affairs.

\section{REFERENCES}

1. W. Bogaerts, P. Bienstman, D. Taillaert, R. Baets, D. de Zutter, "Out-of-plane scattering in photonic crystal slabs", IEEE Phot. Tech. Lett, 13, 565-567, 2001

2. M. Imada, S. Noda, A. Chutinan, M. Mochizuki, T. Tanaka, "Channel drop filter using a single defect in a 2-D photonic crystal slab waveguide”, J. Lightwave Tech., 20, 873-878, 2002

3. O. Painter, R. K. Lee, A. Scherer, A. Yariv, J. D. O'Brien, P. D. Dapkus, I. Kim, "Two-dimensional photonic bandgap defect mode laser", Science, 284, 1819-1821, 1999

4. H. Benisty, Ph. Lalanne, S. Olivier, M. Rattier, C. Weisbuch, T.F. Krauss, C, Jouanin, D. Cassagne, "Finite-depth and intrinsic losses in vertically etched two-dimensional photonic crystals", Opt. Quant. Elec, 34, 205-215, 2002

5. W. Bogaerts, P. Bienstman, R. Baets, "Out-of-plane scattering at sidewall roughness in photonic crystal slabs", Proc. Symposium IEEE/LEOS Benelux Chapter, 79-82, Amsterdam, The Netherlands, 2002

6. A. Talneau, L. Le Gouezigou, N. Bouadma, "Quantitative measurement of low propagation loss at $1.55 \mu \mathrm{m}$ on planar photonic crystal waveguides", Opt. Lett., 26, 1259-1261, 2001

7. T. Happ, A. Markard, M. Kamp, A. Forchel, S, Anand, J.L. Gentner, N. Bouadma, "Nanofabrication of twodimensional photonic crystal mirrors for $1.5 \mu \mathrm{m}$ short cavity lasers", J. Vac. Sci. Technol. B, 19, 2775-2778, 2001

8. M. Mulot, S. Anand, C.F. Carlström, M. Swillo, A. Talneau, "Dry etching of photonic crystals in InP based materials", Physica Scripta, T101, 106-109, 2002

9. A. Djoudi, L. Le Gouezigou, S. Hubert, S. Sainson, C. Moussant, J-P. Chandouineau, F. Pommereau and G-H. Duan, "Fabrication of two-dimensional InP photonic band-gap structures using inductively coupled plasma etching", Proc. 14th Indium Phosphide and Related Materials Conf., Stockholm, Sweden, May 2002 
10. P. Strasser, R. Wüest, F. Robin, D. Erni, H. Jäckel, "Deep dry etching of InP with a Cl2CH4/H2-mixture on an ICPRIE for photonic crystals", Proc. 27th Workshop Compound Semicond. Dev. \& Integrated Circuits, 81-82, Fürigen, Switzerland, May 2003

11. J. Hong, E.S. Lambers, C.R. Abernathy, S.J. Pearton, R.J.J. Shul, "Inductively coupled plasma etching of InGaP, AlInP, and AlGaP in $\mathrm{Cl}_{2}$ and $\mathrm{BCl}_{3}$ chemistries", Journal of Electronic Materials, 27, 132-137, 1998

12. E. Sabin, "Estimation of the activation energy for $\mathrm{Ar} / \mathrm{Cl}_{2}$ plasma etching of InP via holes using electron cyclotron resonance", J. Vac. Sci. technol. B, 16, 1841-1845, 1998

13. S.C. McNevin, "Chemical etching of GaAs and InP by chlorine: The thermodynamically predicted dependence on Cl2 pressure and temperature", Journal of Vac. Sci. Technol. B, 4, 1216-1226, 1986

14. T. Yoshikawa, S. Kohmoto, M. Anan, N. Hamao, M. Baba, N. Takado, Y. Sugimoto, M. Sugimoto, K. Asakawa, "Chlorine-based smooth reactive ion beam etching of indium-containing III-V compound semiconductor", Jpn J. Appl. Phys., 31, 4381-4386, 1992

15. Y. Suzuki, H. Kumano, W. Tomota, N. Sanada, Y. Fukuda, "Nitridation of an $\operatorname{InP}(001)$ surface by nitrogen ion beams", Applied Surface Science, 162-163, 172-177, 2000

16. R.A. Gottscho, C.W. Jurgensen, D.J. Vitkavage, "Microscopic uniformity in plasma etching", J. Vac. Sci. Technol. $B, \mathbf{1 0}, 2133-2147,1992$ 